East African Journal of Science, Technology and Innovation, Vol. 2 (4): September 2021

This article is licensed under a Creative Commons license, Attribution 4.0 International (CC BY 4.0)

\title{
Applying conjoint analysis to match farmer's preferences for cattle traits with those conferred by the improved trypanotolerant Orma Boran cattle in coastal Kenya
}

\author{
${ }^{1 *}$ MUGUNIERI L., WANJALA K., ALUSI P., KURGAT R., GAMBA D., OKOTH S. \\ 1*Kenya Agricultural and Livestock Research Organization (KALRO) \\ *Corresponding author: Lawrence.Godiah@kalro.org
}

\begin{abstract}
Bovine trypanosomiasis is a key constraint to increased livestock production across all production systems of Kwale County in coastal Kenya. Genetically controlled trypanotolerance of cattle is regarded as one of the promising methods available to mitigate the impact of this disease, and the improved trypanonotolerant Orma Boran is one of the breeds available in Kenya for this purpose. Conjoint analysis was thus used to match farmer's preference for cattle traits against those conferred by this breed in three production systems of Kwale County. The study also estimated the transaction costs (TC) that would influence access to breeding services while availing the breed. The aim was to identify production systems where the breed matches well with farmer preferences, as an initial step towards its dissemination. In order of importance, farmers preferred cattle that were resistant to trypanosomiasis, had large body size, exhibited resistance to tick-borne-diseases (TBD), and had high milk output. However, there were interproduction system differences in trait preferences, where resistance to TBD was least valued in agropastoral system, with more emphasis put on size of animal and trypanotolerance respectively. On the other hand, in medium potential and marginal pastoral systems, more emphasis was placed on TBD resistance, followed by trypanosomiasis resistance. The agro-pastoral production system was therefore delineated as a potential area for disseminating the breed. Regarding transaction costs, price of service was the most important transaction costs element. Furthermore, whereas bull service was preferred over artificial insemination (AI) services in marginal pastoral and medium potential systems, AI was given preference in agro-pastoral system. It was thus concluded that the Orma Boran dissemination would be successful among agro-pastoral households system, and should be delivered using subsidised AI services.
\end{abstract}

\section{Keywords: Cattle; Orma Boran; Conjoint analysis; Trypanotolerance; Kenya}

Cite as: Mugunieri et al., (2021) Applying conjoint analysis to match farmer's preferences for cattle traits with those conferred by the improved trypanotolerant Orma Boran cattle in coastal Kenya. East African Journal of Science, Technology and Innovation 2(4).

\section{Received:}

Accepted:

Published:
$01 / 12 / 20$

$31 / 08 / 21$

25/09/21

\section{Introduction}

Trypanotolerance is defined as the relative capacity of an animal to control the development of trypanosome parasites and limit their pathological effects, the most important being anaemia (d'Ieteren et al., 1998). Genetically controlled trypanotolerance of cattle is regarded as a promising method for control of trypanosomiasis since the permanent nature of genetic improvement implies that benefit to cost ratios for development and dissemination are often high (d'Ieteren et al., 1998). However, the long period it takes to breed a trypanotolerant cattle has limited the numbers that are available for use. 
In Kenya, one such breed available for adoption by farmers is the improved Orma Boran cattle. Between 1983 and 2002, Biotechnology Research Institute of the Kenya Agricultural and Livestock Research Organisation (KALRO-BioRI), then operating as the Kenya Trypanosomiasis Research Institute (KETRI) established an Orma breeding herd, to improve and conserve the unique genetic pool by collecting and preserving semen for dissemination to willing farmers in tsetse infested and trypanosomiasis endemic areas. Details on the improvement history and qualities of the trypanotolerant Orma Boran has been extensively reviewed by Dolan (1998). In summary, the breed produces more milk than the traditional African Zebu with off take of 3.02 litres per day under natural arid and semi arid conditions. It grows faster with a calving age of 51 months, a calving interval of 12 months, and attains a mature weight of about $400 \mathrm{~kg}$ in four years for bulls (Dolan, 1998; Njogu et al., 1998). Orma Boran cattle are therefore important to stakeholders in tsetse and trypanosomiasis endemic areas because of their ability to withstand trypanosomiasis infection, a fatal disease constraining livestock production in subSaharan Africa.

Despite availability of this breed, limited effort has been made to distribute it to livestock keepers, ostensibly due to lack of information to guide the dissemination process in different production systems. Although many studies focusing on farmer preferences for cattle traits have been undertaken in Kenya (e.g. Ouma et al., 2007; Makokha et al., 2007; Scarpa et al., 2003), none of them provides sufficient information to enable dissemination of this improved breed of cattle. Evaluating farmer trait preferences against those confered by the Orma Boran would be important in designing of an effective dissemination strategy for the trypanotolerant cattle. It is expected that adoption of resistant genotypes would not only raise cattle productivity, but will also promote better landuse practices, like reduced bush clearing and limited use of synthetic pyrethroids for control of tse-tse flies, and a reduction in the use of trypanocides to control the disease ( $\mathrm{d}^{\prime}$ Ieteren et al., 1998).
This study was designed to undertake two principle tasks. First, to establish the extent to which the traits of improved trypanotolerant Orma Boran breed are in tandem with livestock keepers cattle trait preferences in three production systems endemic with animal trypanosomiasis in Kwale County. Second, to estimate the importance of different transaction costs items that farmers encounter while accessing breeding services that confer the preferred traits. The information generated was used to guide in the selection of areas for dissemination of the breed as well as the approach to use in order to mitigate the effect of bovine trypanosomiasis in the County. According to the Kwale County Integrated Development Plan (CIDP) of 2018 to 2022, bovine trypanosomiasis was one of the main constraints identified as limiting increased livestock production in the county (Kwale, 2018).

\section{Materials and Methods}

\section{Theoretical framework}

This study used the conjoint analysis that falls under the consumer theory based on arguments put forth by Sy et al., (1997). The authors note that the estimation of the marginal contribution of the specific cattle characteristics to the overall performance in the livestock production system can be approached theoretically from two perspectives. First, one can estimate the production function where the marginal physical products and marginal value products for desirable traits are derived (Ladd and Gibson, 1978). Alternatively, one can utilise the demand theory, where the consumer is the focal point (Ladd and Suvannunt, 1976). Sy et al., (1997) argues that these two approaches are similar, where the producers' underlying objective function (in the former) is transformed into a utility function (in the latter). However, empirically and based on their arguments, there is one key issue in the livestock production system in sub-Saharan Africa that makes the consumer approach more preferable than the production function approach. The system is highly probabilistic in nature (i.e. a farmer buying cattle with desirable traits like high milk output does not assure that the characteristic will be passed on to each offspring), implying that the underlying profit function may not be 
deterministic. This means that the producer's objective function may not be simple in structure and may include risk preferences. Therefore, the specification of the production function would require specifying the risk preferences, which may not be an easy task. This problem is however avoided when one utilises the consumer demand approach. This empirical consideration made the consumer approach more suitable for use in this study.

\section{Study area and sampling}

Kwale County was purposively selected as a pilot study area because it has three production systems where cattle are faced by different constraints, including differences in levels of risk of exposure to different diseases like trypanosomiasis and TBDs. These production systems sequentially cover five agro-ecological zones (AEZ's), ranging from medium to extremely low agro-ecological potentials (Jaetzold \& Schmidt (1983). These are Sugarcane Zone (CL2), Coconut-Cassava Zone (CL3) and Cashew nut-Cassava Zone (CL 4) that form the medium potential mixed farming zones with an area of 208,500ha; the Livestock-Millet Zone (CL5) that is categorised as marginal agropastoral $(234,200 \mathrm{ha})$, and the Ranching Zone (CL6) which is arid pastoral $(288,600 \mathrm{ha})$.

Sites with similar level of risk of exposure to bovine trypanosomiasis were selected from each production system. This risk was derived from secondary data on point prevalence of trypanosomiasis in cattle spanning 10 years (1999 to 2018). The data was obtained from KALRO, International Centre for Insect Physiology and Ecology (ICIPE), and Kenya Tsetse and Trypanosomiasis Eradication Council (KENTTEC). This data was validated through an experts participatory workshop to produce a trypanosomiasis risk map. During the mapping, blocks were delineated in goggle earth and categorized based on their level of risk. The risk levels were grouped as: (i) high risk, where prevalence rate was above $4 \%$; (ii) medium risk, where prevalence rate was between $2-4 \%$; and, (iii) low risk, with prevalence rate of between 0 $1 \%$. The risk map was then overlaid with agroecological zones, based on the FAO (1996) AEZ grouping, i.e. (AEZ308-345- pastoral; AEZ346393-agropastoral; and, AEZ394-413- medium potential) to give a map of the risk levels against the AEZ. Based on the overlaid map, one administrative ward each, with high trypanosomiasis risk was purposively sampled from both pastoral and agro-pastoral AEZ's, while one with medium risk was sampled from the medium potential AEZ (due to absence of one with high risk). These wards were Ramisi for mixed system, Vanga for agro-pastoral and Samburu/Chengoni for pastoral. From each ward, two villages were randomly sampled from a list of villages available at the wardadministrative offices. For each village, a list of livestock keepers was drawn, and two enumerators recruited and trained on how to conduct the survey. Thirty households were randomly sampled from each village for administration of the questionnaire as well as implementation of the conjoint survey, all prepared and pretested a priori, to give a total sample of 180, with 60 from each production system. The production system was the unit of reference in data analysis. The number of villages sampled from each ward, as well as households sampled from each village was determined based on budget considerations. The survey questionnaire covered basic questions on household demographics, asset ownership as well as farm and non-farming activities. The conjoint survey instrument was prepared as described below.

\section{Selection and ranking of cattle traits and transaction costs attributes used in preference measurement}

The improved Orma Boran breeding program was designed to accommodate dissemination of bull services, and thus, nine bull traits were initially selected from various studies focusing on farmer preferences for bull traits in tropical Africa (Sy et al., 1997; Tano et al., 2003; Makhoka et al., 2007; and Ouma et al., 2007). The traits included: (i) trypanotolerance - bull that is resistant to trypanosomiasis; (ii) tick borne disease (TBDs) resistance - bull that is resistant to TBDs; (iii) traction fitness - bull that is good for traction; (iv) size - bull that is of big size; (v) weight gain - bull that grows fast; (vi) temperament - bull that is easy to handle; (vii) feeding ease - bull that eats a wide variety of forage; (viii) fertility- bull that can successfully 
serve many cattle within a given time; and, (ix) colour - bull that is off-white in colour.

On the other hand, although studies focusing on transaction costs incurred by farmers in tropical Africa while accessing breeding services is slim, the study used the nomenclature provided by Randolph and Ndung'u (2000) in their investigation of transaction costs associated with accessing livestock health services in Kenya. The transaction costs attributes included price, source of service, reputation of service provider, distance from the service, extra services offered by the service provider, and promptness of service. This nomenclature was adopted as follows. Price of service comprised both the cost of the genetic material, plus the associated service fees. Sources through which genetic materials can be disseminated were identified as natural bull services and artificial insemination (AI). The choice of a source was influenced by two forms of risk, i.e., the likely failure to realise conception of the served cattle and the risk of spread of diseases. Bull service was associated with high risk of disease spread and low levels of conception failure while AI was associated with low levels of disease spread, but with a degree of conception failure.

Regarding reputation, the more known the service provider's reputation, the lower the potential transaction costs in terms of needing to seek additional information before considering the service provider as a potential source. Distance as an attribute captured both the direct transport and time costs taken to contact the service provider, and the other transaction costs such as access to information about the person and potential information asymmetries, and the likelihood of finding the provider in place of business. Extra services referred to the additional services that are provided together with the main service, at no extra cost. Two forms of extra services were considered, i.e., credit and free advice. Lastly, promptness of service entailed a dimension of reliability the service provider responds to a service call. This is very critical in dissemination of the Orma Boran since cattle are only on heat for a period of 24 hours. The longer the delay, the larger the risk that the services will be ineffective. For the service providers keeping bulls, this is intended to represent a situation where the farmer will readily obtain the services on visiting the agent, or will need to make repeat visits.

The selected cattle traits and transaction costs attributes were evaluated through key informants' interviews (KII's) for ranking in order of importance in each production system. In addition, for each of these traits/attributes, information was sought on the appropriate number (and magnitude) of levels. Caution was taken such that the levels presented offered concrete and unambiguous meanings. Besides, in coming up with levels, it was important to note that holding all else constant, attributes defined on more levels than others were more likely to be biased upwards in importance. For example, price defined as (KSh 100, KSh 200, KSh 300, KSh 400 , KSh 500) was more likely to receive higher relative importance than when defined as (KSh 100 , KSh 250, KSh 500) even though the same price range was measured (see Wittink et al., 1989). This also applied to all other quantitative attributes (like Milk yield) as well as categorical (Ability to graze wide forage, Colour etc.). To be able to control for this, more or less similar number of levels were used for every attribute.

Based on the ranking by key informants, only the top four bull traits and top three transaction cost attributes were used in designing the final conjoint survey so as to reduce complexity and minimize respondent fatigue (Tano et al., 2003). This gave 12 profiles for transaction costs and 16 for the cattle traits. From this, a sub-set of 12 profiles for cattle traits (Table 1) and 10 for transaction costs (Table 2) were selected using DATA/ORTHOGONAL DESIGN command in SPSS (SPSS, 1994). Two preference ranking were thus conducted, one for bull traits and the other for transaction costs attributes. Cards with pictorial representations of the differences in levels of traits and attributes were used to demonstrate each cattle or transaction cost profile to survey respondents.

As outlined in Tano et al., (2003), response elicitation began with the enumerator explaining the meaning of the levels of traits/attributes that were presented by special drawings. The cattle owner was then asked to explain his/her understanding of the level of traits. Respondents 
then evaluated these profiles and ranked them in order of preference. A ranking of profiles was recorded in a form.

Table 1. Twelve randomized combinations of bull trait attributes presented to farmers for preference ranking

\begin{tabular}{lcccc}
\hline Card & $\begin{array}{c}\text { Trypanosomiasis } \\
\text { Resistance }\end{array}$ & $\begin{array}{c}\text { Tick Borne Disease } \\
\text { (EFC) Resistance }\end{array}$ & Milk Output & Body Size \\
\hline 1 & Resistant & Susceptible & Low & Small \\
2 & Resistant & Resistant & High & Big \\
3 & Susceptible & Susceptible & High & Small \\
4 & Susceptible & Resistant & Low & Small \\
5 & Susceptible & Resistant & Low & Big \\
6 & Susceptible & Susceptible & High & Big \\
7 & Resistant & Susceptible & Low & Big \\
8 & Resistant & Resistant & High & Small \\
9 & Susceptible & Resistant & High & Big \\
10 & Susceptible & Resistant & High & Small \\
11 & Resistant & Susceptible & High & Small \\
12 & Resistant & Susceptible & High & Big \\
\hline
\end{tabular}

Table 2. Ten randomized combinations of transaction costs attributes presented to farmers for preference ranking

\begin{tabular}{lccc}
\hline Card & Price for service (KSh) & Method of service & Distance to service (km) \\
\hline 1 & 500 & AI & $0-5$ \\
2 & $1000-2000$ & AI & $0-5$ \\
3 & 500 & AI & $10-25$ \\
4 & $>2000$ & Natural & $10-25$ \\
5 & $1000-2000$ & Natural & $10-25$ \\
6 & $>2000$ & Natural & $0-5$ \\
7 & $1000-2000$ & Natural & $0-5$ \\
8 & 500 & Natural & $10-25$ \\
9 & $>2000$ & AI & $0-5$ \\
10 & 500 & Natural & $0-5$ \\
\hline
\end{tabular}

$0-5 \mathrm{~km}=$ walking distance $10-25 \mathrm{~km}=$ motocycling distance

\section{Data analysis}

Data collected was used for empirical parameter estimation with the model reflecting relations between profile evaluation and the values of the attributes that characterize them. The empirical estimation involved the use of the traditional conjoint analysis using statistical package $\mathrm{R}$ on stated consumer preferences using OLS estimation with dummy variables, viz:

$$
\widetilde{U}_{s}=b_{0 s}+b_{1 s} X_{1 s}+b_{2 s} X_{2 s}+\ldots .+b_{n s} X_{n s}
$$

Where: $\widetilde{U}_{s}$ - theoretical utilities perceived by s-th respondent; $b_{0 s}$ - intercept; $b_{1 s}, \ldots \ldots \ldots . b_{n s}$ parameter estimates of the regression model (i.e. the partworth utilities of transaction costs attribute/cattle trait levels); s - number of respondents in the survey; and, $\mathrm{X}_{1}, \ldots \ldots \ldots \ldots, \mathrm{X}_{\mathrm{n}}$ dummy variables representing different cattle traits of transaction costs attributes.

Using function caModel() from conjoint package, this model was calculated for each production zone as well as jointly for all the systems. In addition, caImportance() was used to calculate importance of all attributes. The function returned a vector of percentage attributes' importance, with the sum of importance being $100 \%$. Function caUtilities() calculated partworth utilities of attribute's levels for whole sample of respondents as well as for each production zone. The function returned vector of 
utilities, with the length of this vector being equal to number of all levels. Besides these models, other questionnaire data was analysed using descriptive statistics.

\section{Results}

Socio-economic characteristics and livestock health indicators of farmers in different production systems

All the 180 farmers successfully completed the conjoint experiment and the questionnaire survey questionnaire. Table 3 provides a summary of household demographics as well as livestock health indicators of these farmers.

Table 3. Household demographics and livestock health indicators of the surveyed livestock keepers

\begin{tabular}{|c|c|c|c|c|}
\hline \multirow[t]{2}{*}{ Means } & \multicolumn{4}{|c|}{ Production system } \\
\hline & $\begin{array}{r}\text { Mixed farming } \\
\mathrm{n}=60\end{array}$ & $\begin{array}{r}\text { Agro- } \\
\text { pastoralism } \\
\mathrm{n}=60\end{array}$ & $\begin{array}{r}\text { Pastoralism } \\
\mathrm{n}=60\end{array}$ & $\begin{array}{r}\text { All systems } \\
\mathrm{n}=180\end{array}$ \\
\hline Age (years) & $51.78^{a}(18)$ & $53.83^{\mathrm{a}}(9.7)$ & $52.48^{a}(14.7)$ & $52.43(14.5)$ \\
\hline Size of household (no.) & $6.18^{\mathrm{a}}(3.2)$ & $7.9 \mathrm{a}(7.2)$ & $12.05(6.6)^{b}$ & $8.67(6.4)$ \\
\hline $\begin{array}{l}\text { Household head formal } \\
\text { education (years) }\end{array}$ & $5.97(4.33)$ & $8.43(4.35)$ & $3.03(4.11)$ & $5.81(4.79)$ \\
\hline Dairy cattle (heads) & $0.13^{\mathrm{ab}}(0.81)$ & $0.43^{\mathrm{b}}(1.21)$ & $0.02^{\mathrm{a}}(0.13)$ & $0.19(0.86)$ \\
\hline Local cattle (heads) & $6.2^{\mathrm{a}}(4.23)$ & $8.83^{a}(5.56)$ & $15.76(13.8)$ & $9.92(9.44)$ \\
\hline Sheep and goats (heads) & $2.2(3.3)$ & $7.6(8.77)$ & $19.24(15.93)$ & $9.38(12.56)$ \\
\hline $\begin{array}{l}\text { Cattle treated for infection in } \\
\text { last one year (heads) }\end{array}$ & $1.37^{a}(1.7)$ & $1.12^{\mathrm{a}}(2.1)$ & $3.43(6.1)$ & $1.94(3.9)$ \\
\hline $\begin{array}{l}\text { Cattle mortalities recorded } \\
\text { in last one year (heads) }\end{array}$ & $0.73^{a}(1.3)$ & $0.14^{\mathrm{a}}(0.4)$ & $1.7(3.3)$ & $0.8(2.1)$ \\
\hline $\begin{array}{l}\text { Ratio of treated cattle to } \\
\text { herd seize }\end{array}$ & $0.26(0.4)$ & $0.11^{\mathrm{a}}(0.2)$ & $0.17^{a}(0.3)$ & $0.18(0.3)$ \\
\hline $\begin{array}{l}\text { Ratio of cattle mortalities to } \\
\text { herd size }\end{array}$ & $0.13(0.3)$ & $0.01^{\mathrm{a}}(0.1)$ & $0.09 \mathrm{a}(0.2)$ & $0.08(0.2)$ \\
\hline
\end{tabular}

Figures in brackets represent standard deviation

Figures without the same superscript across rows are significantly different $(\mathrm{P}<0.05)$ - Least Significant Difference

Most $(70 \%)$ of the households were headed by males. There were no significant differences between male and female headed households with regard to herd size (for local and dairy cattle, as well as sheep and goats). However, family sizes of female headed households were significantly smaller $(\mu=7.3 ; \mathrm{SD}=4.3)$ compared to male $(\mu=9.3 ; \mathrm{SD}=7.0)$. In addition, heads of female headed households possessed significantly lower level of years of formal education $(\mu=4.3 ; \mathrm{SD}=4.8)$ compared to their male counterparts $(\mu=6.5 ; \mathrm{SD}=4.7)$. Across production systems, farmers in agro-pastoral areas had significantly more years of formal education and owned comparatively larger herds of dairy animals. Cattle morbidities, captured as the total number of cattle recorded as being offhealth and requiring treatment in the last one year preceding the survey were significantly higher in pastoral areas, perhaps corresponding to the significantly larger herd sizes. The same applied to the absolute number of recorded mortalities during the one-year period preceding the survey. However, in relative terms, the ratio of morbidities and mortalities were significantly higher in mixed systems compared to the rest.

\section{Relative importance of cattle traits attributes} The relative importance estimates for every cattle trait attribute was estimated by using caImportance()command in R conjoint. This was the relative importance of the attribute in percentage terms in the farmers' decisionmaking process (with the importance scores for all the attributes summing to 100). The importance scores served as the indicator for 
comparing the importance of other cattle traits vis-à-vis trypanosomiasis resistance (trypanotolerance) in farmers' choice of cattle breeding services (Table 4).

Table 4. Relative importance of cattle trait attributes

\begin{tabular}{lrrrr}
\hline & \multicolumn{2}{c}{ Relative importance (\%) } & All systems \\
& Mixed farming & Agro-pastoralism & Pastoralism & $\mathrm{n}=180$ \\
\hline Trypanosomiasis resistance & 29.49 & $\mathrm{n}=60$ & $\mathrm{n}=60$ & 31.40 \\
TBD resistance & 32.34 & 33.50 & 31.44 & 23.86 \\
High milk output & 20.06 & 13.27 & 34.85 & 16.54 \\
Large body size & 18.10 & 47.31 & 14.97 & 28.20 \\
\hline
\end{tabular}

Overall, trypanotolerance was the most important trait jointly across the three production zones, followed by large body size, resistance to TBDs and high milk output in that order. However, at production system level, trypanotolerance was ranked second in all production systems; coming second to resistance to TBDs in mixed and pastoral systems, and large body size in agro-pastoral system. What stands out is the minimal importance attached to resistance to TBDs in agro-pastoral areas. Importance of cattle traits went hand in hand with utility levels attached to each trait by the

Table 5. Partworth/Utilities for different levels of cattle traits farmers. Table 5, which gives the levels of utilities/partworth of each level for every attribute. Utilities were derived from the caUtilities() function in R, where the command decomposed each farmers' rankings of each set of the orthogonal combinations to directly estimate the proportional contribution, or the partworth, of each attribute level to the 'total worth' expressed in the ordinal ranking of the combinations. The estimated partworth represents an internally consistent utility value of the individual attribute level.

\begin{tabular}{lrrrr}
\hline & Mixed farming & Utility level & & \\
& $\mathrm{n}=60$ & $\mathrm{Agro}-$ pastoralism & Pastoralism & All systems \\
& 6.732 & $\mathrm{n}=60$ & $\mathrm{n}=60$ & $\mathrm{n}=180$ \\
\hline Intercept & 1.208 & 6.684 & 6.641 & 6.686 \\
Trypanosomiasis resistance & -1.208 & 1.231 & 0.977 & 1.140 \\
Trypanosomiasis susceptible & 1.325 & -1.231 & -0.977 & -1.140 \\
TBD resistance & -1.325 & 0.194 & 1.083 & 0.866 \\
TBD susceptible & 0.822 & -0.194 & -1.083 & -0.866 \\
High milk output & -0.822 & 0.511 & 0.465 & 0.600 \\
Low milk output & 0.742 & -0.511 & -0.465 & -0.600 \\
Body size & -0.742 & 1.739 & 0.582 & 1.023 \\
Small body size & -1.739 & -0.582 & -1.023 \\
Residual standard error/df & $0.955 / 715$ & $2.707 / 715$ & $3.167 / 703^{*}$ & $3.034 / 2143^{*}$ \\
Multiple R-squared & 0.2756 & 0.3898 & 0.1638 & 0.231 \\
Adjusted R-squared & 0.2715 & 0.3864 & 0.1591 & 0.230 \\
F-statistic/df & $68 / 715$ & $114.2 / 715$ & $34.44 / 703$ & $160.9 / 2143$ \\
p-value & $<2.2 \mathrm{e}-16$ & $<2.2 \mathrm{e}-16$ & $<2.2 \mathrm{e}-16$ & $<2.2 \mathrm{e}-16$ \\
\hline
\end{tabular}

It is thus apparent that farmers in the agropastoral system devoted most of their effort in selecting cattle that were of large body size provided they are trypanotolerant, while giving 
less attention to resistance to TBD. On the other hand, in mixed and pastoral areas, more utility was derived from animals that were resistant to TBD, while at the same time being trypanotolerant.

\section{Relative importance of the transaction costs attributes}

The relative importance of the transaction cost attributes is given in Table 6 .

Table 6. Relative importance of transaction costs attributes for livestock keepers

\begin{tabular}{|c|c|c|c|c|}
\hline & \multicolumn{4}{|c|}{ Relative importance (\%) } \\
\hline & $\begin{array}{r}\text { Mixed } \\
\text { farming } \\
n=60\end{array}$ & $\begin{array}{r}\text { Agro- } \\
\text { pastoralism } \\
n=60\end{array}$ & $\begin{array}{r}\text { Pastoralism } \\
n=60\end{array}$ & $\begin{array}{r}\text { All systems } \\
n=180\end{array}$ \\
\hline Price of service & 61.94 & 44.76 & 54.19 & 52.47 \\
\hline Method of delivery & 10.34 & 37.25 & 41.83 & 43.51 \\
\hline Distance to source & 27.73 & 17.99 & 3.98 & 4.02 \\
\hline
\end{tabular}

Overall, more importance was given to price of breeding services, followed by mode of delivery and lastly by distance to source of service. However, whereas price was rated highest across all production systems, distance to source was rated as being more important in mixed systems when compared to mode of delivery; while the reverse was true in agro-pastoral and pastoral systems. In fact, the importance attached to distance was quite low in pastoral areas, perhaps due to the mobile nature of cattle often witnessed in pastoral productions systems in Kenya.

Table 7. Partworth/Utilities for different levels of transaction costs

\begin{tabular}{|c|c|c|c|c|}
\hline & \multicolumn{4}{|c|}{ Utility level } \\
\hline & $\begin{array}{r}\text { Mixed farming } \\
\mathrm{n}=60\end{array}$ & $\begin{array}{r}\text { Agro- } \\
\text { pastoralism } \\
\mathrm{n}=60\end{array}$ & $\begin{array}{r}\text { Pastoralism } \\
\mathrm{n}=60\end{array}$ & $\begin{array}{r}\text { All systems } \\
\mathrm{n}=180\end{array}$ \\
\hline Intercept & 6.058 & 5.754 & 5.734 & 5.849 \\
\hline Service price above KSh 2000 & -1.741 & -2.325 & -1.001 & -1.693 \\
\hline $\begin{array}{l}\text { Service price between KSh } \\
1000 \text { \& KSh } 2000\end{array}$ & 0.804 & 0.165 & 0.136 & 0.37 \\
\hline Service price about KSh 500 & 0.937 & 2.16 & 0.865 & 1.323 \\
\hline AI service & -1.413 & 0.682 & -0.383 & -0.372 \\
\hline Bull service & 1.413 & -0.682 & 0.383 & 0.372 \\
\hline $\begin{array}{l}\text { Service available within } \\
\text { walking distance (i.e. } 5 \mathrm{~km} \\
\text { radius) }\end{array}$ & 0.655 & 0.807 & 0.445 & 0.637 \\
\hline $\begin{array}{l}\text { Service available beyond } \\
\text { walking distance }(10-25 \mathrm{~km})\end{array}$ & -0.655 & -0.807 & -0.445 & -0.637 \\
\hline Residual standard error/df & $2.342 / 595$ & $1.881 / 595$ & $2.789 / 585$ & $2.538 / 1785$ \\
\hline Multiple R-squared & 0.33 & 0.58 & 0.10 & 0.204 \\
\hline Adjusted R-squared & 0.32 & 0.57 & 0.10 & 0.202 \\
\hline F-statistic/df & $72.77 / 595$ & $202.7 / 595$ & $12.72 / 585$ & $114.2 / 1785$ \\
\hline $\mathrm{p}$-value & $<2.2 \mathrm{e}-16$ & $<2.2 \mathrm{e}-16$ & $<2.2 \mathrm{e}-16$ & $<2.2 \mathrm{e}-16$ \\
\hline
\end{tabular}

Table 7 gives the utility levels farmers in different production systems attach to different levels of the transaction costs attributes. Lower utility was attached to higher prices, and this was more pronounced in agro-pastoral areas. This was followed by distance to service, with services that were nearer attracting more utility compared to those that were far, and there after form of service 
in that order. However, it is important to note that whereas more utility was attached to bull service in mixed and pastoral areas, the opposite was true in agro-pastoral areas where there was higher preference for AI services.

\section{Discussion}

\section{Production circumstances of the surveyed farmers}

According to the Kwale County Strategic Development of 2018-2022, the county has approximately 190,988 local breed cattle; 5,475 improved dairy cattle; 3,371,126 goats and 54,578 sheep, most of which are distributed across the agro-pastoral and pastoral (CL 5 and 6) livelihood zones (Kwale, 2018). This study has however shown that whereas households residing in CL6 own significantly larger herds of local cattle and flocks of small ruminants, those in CL5 own significantly larger herds of improved dairy cattle. There were significantly higher incidences of morbidity and mortalities in mixed systems (CL4), followed by pastoral (CL6), and much lower in agro-pastoral zones (CL5). These findings were made despite all the surveyed areas having similar risk of exposure to trypanosomiasis.

The apparent differences in morbidities and mortalities could thus be attributed to others livestock diseases found in the study area. Kwale County has identified in order of importance, trypanosomiasis, East Coast fever (ECF) and Anaplasmosis as the three most important diseases affecting cattle production (Kwale, 2018). Several studies have investigated and documented prevalence and epidemiology of these diseases in Kwale and other coastal areas in Kenya. Muraguri et al., (2005) analysed and compared disease incidences in 130 calves in 67 farms in Kwale. The study reported incidences of ECF $(23.1 \%)$ and trypanosomiasis $(29.1 \%)$ as being among the highest vector-borne diseases. The corresponding mortality incidence rates of ECF and trypanosomiasis were 10.9 and 3.6\%, respectively, implying that whereas trypanosomiasis was more widespread, EFC resulted in more fatalities. The annual incidence rates of anaplasmosis and babesiosis were 10.9 and $1.2 \%$, respectively. There was no mortality arising specifically from anaplasmosis or babesiosis. On the other hand, Maloo et al., (2001a) and Maloo et al., (2001b) analysed both incidences of ECF and trypanosomiasis in cattle, as well as epidemiology of the diseases as one moves across different AEZs. The results showed that ECF and trypanosomiasis were the most important. Over $70 \%$ of the small-holder dairy cattle sampled had antibodies or antigens to tickborne diseases (TBD), while a relatively lower trypanosome antigen (33\%) and antibody prevalence (55\%) were observed. With regard to ECF, Theileria parva antibody prevalence's decreased as one moved from the wetter AEZs, CL3 and CL4, to the drier CL5 AEZ. Similarly, this study reported decreasing of morbidities and mortalities as one moves from mixed system (CL3 \&4) to agro-pastoral areas CL5. Lastly, studies have shown increased incidences of tickborne diseases in livestock in areas where they interphase with wildlife (Okal et al., 2020; Caron et al., 2013). The administrative ward sampled in the mixed farming system (i.e. Ramisi ward) border Shimba Hill National Reserve, being one of the largest coastal forests in East Africa covering an area of about 300 square kilometres and home to over 20 wildlife species. On the other hand, in the pastoral system, Samburu/Chengoni ward is adjacent to the expansive Tsavo National park. In the two areas, the mixing of animals from the wild and the domestic ecosystem acts as a route of introducing diseases into the latter, thus increasing risk to parasitic infections (Munang'andu et al., 2012). The foregoing factors, could likely explain farmers' estimated morbidities rates of $26 \%$ for mixed, $11 \%$ for agro-pastoral and $17 \%$ for pastoral areas, and mortality rates of 13,1 and $9 \%$ respectively. This implies that whereas the risk of exposure to trypanosomiasis was likely to be the same in the study areas, the risk to TBD increased progressively from agro-pastoral to pastoral and was more intense in mixed system areas. This perhaps explains why farmers in mixed and pastoral systems ranked TBD resistance trait above trypanotolerance.

\section{Relative importance and preference for trypanotolerance cattle trait}

Jointly across all production systems, trypanosomiasis resistance was the most preferred cattle trait for all the surveyed farmers. This was followed by big body size, resistance to 
tick borne diseases and high milk output in the second, third and fourth positions respectively. This implies that farmers' desire to manage trypanosomiasis overrides other concerns in their endeavour to rear livestock. Farmers' preference for trypanotolerance over other traits may be due to the fact that trypanosomiasis is identified as the most important wide-spread disease constraint on livestock in sub-Saharan Africa, where it causes mortality and morbidity in livestock (Eisler et al., 2002). Trypanosomiasis costs Africa about US $\$ 4.5$ billion a year compared to East Coast fever (ECF) losses of about US\$168, million (Budd, 1999; Kristjanson et al., 1999). In Kenya, increased trypanosomiasis risk represented by an increased disease prevalence from $1 \%$ to $20 \%$ has been shown to decrease the density of cattle by about $53 \%$, and is associated with an increase of calving interval from about 14 to 25 months among the dairy farmers (Mugunieri and Matete, 2005).

It is however important to mention that within all production systems, trypanosomiasis resistance ranked second, behind large body size in the agro-pastoral system, and TBD resistance in mixed and pastoral systems. As mentioned earlier, the improved Orma Boran cattle breed, besides being resistant to trypanosomiasis, produces more milk than the normal African Maasai Zebu, grows faster, and the males attain a relatively higher mature weight of about $400 \mathrm{~kg}$ in four years for bulls (Dolan, 1998; Njogu et al., 1998), meaning that they have a large body size. This implies that the breed fits well with the requirements of farmers in agro-pastoral areas, than would for those in pastoral or mixed systems.

The apparent high risk of exposure to both trypanosomiasis and TBDs in mixed systems and pastoral areas is perhaps the reason why farmers in these areas preferred cattle that were resistant to both diseases, but ratings TBD resistance higher than trypanotolerance; i.e. at $30 \%$ for trypanotolerance and 32\% for TBD resistance in mixed systems, and 31\% for trypanotolerance and $35 \%$ for TBD in the pastoral system. This implies that farmers in pastoral and mixed systems attached more utility to TBD resistance trait than those that conferred trypanotolerance.
Relative importance of transaction costs influencing access to preferred breeding services

Results of the transaction costs conjoint models reveal that the price of breeding service was the most important transaction cost item, followed by method of breeding service (natural service vs. artificial insemination) and distance to the service. The attributes identifying the various breeding service options were chosen so as to represent almost real-life decision options that farmers may use. The results indicate that price is the most important attribute in the choice of breeding services, and the identification of price as the most important of the three attributes was expected. The price levels presented covered a gradual increase of KSh 500, followed by an increase of between KSh 1000-2000, and thereafter to beyond KSh 2000. It is apparent that this increase (from subsidised levels, to the current market level charges for most breeding services, and thereafter higher than market levels), was sufficient enough from discouraging many farmers from choosing stimuli with higher price. That farmers gave price such a high weight in choice of breeding services (from $45 \%$ to $65 \%$ across production systems) reflects in part that breeding services may not be an input that farmers are ready to pay a premium for, and that any price increase would be unacceptable since avoiding such services may not lead to direct losses but would curtail future benefits for which farmers may be willing to forego. That is to say, by avoiding high prices, farmers will not become worse-off, neither will they become better-off, but will remain as they are.

The second attribute in order of importance was the type of source of the breeding service, in this case, natural service vs. artificial insemination, with importance ranging from $10 \%$ to $42 \%$ across production systems. This transaction attribute is associated with three forms of risk. First, the risk of conception failure associated with poor timing of heat signs in cattle or poor training for AI service providers, and this risk was identified to be higher for AI services. Second, the risk of contracting sexually transmitted diseases, which was higher for natural services. Third, the risk associated with the probabilistic nature of the livestock production system (i.e. a farmer sourcing for desirable traits like large body size does not assure that the characteristic will be 
passed on to each offspring), which was more or less similar between natural breeding and AI services. Farmers' preference for either of the service type depended on what risk they were willing to take. Apparently, most farmers in pastoral system were more averse with likelihood of conception failure than were with risk of disease transmission; with the reverse holding in agro-pastoral systems. In mixed systems, minimal weight seems to have been put on source of service.

Distance was the least important of the three transaction cost attribute, particularly in pastoral systems. This attribute embodies not only the direct transport and time costs in going to search for the service provider, but also other transaction costs such as access to information about the person and the ability to monitor services of such a provider to ensure that she makes the necessary efforts to respond to service requests or redress complaints. The more distant a service provider is from the farmer, the higher will be these costs. However, farmers valued such costs lower than those related to price and to source of service.

These results provide evidence that transaction costs play an important role in farmers' choice of breeding services. Based on arguments by Randolph and Ndung' $u$ (2000), this conclusion is based on three key assumptions: first; the scenario presented in this study simulates a real decision making situation for livestock keepers; second; the selected attributes are valid proxies for transaction costs; and third, that the conjoint analysis adequately measures farmers' preferences and intended actions. However, Randolph and Ndung'u (2000) conclude that establishing the link between the selected attributes and transaction costs will require a different type of approach, possibly involving anthropological evaluations of farmer perceptions.

\section{Conclusion}

This study applied the conjoint analysis to attain two objectives. First, to establish the extent to which the traits which the improved trypanotolerant Orma Boran breed conferred were in tandem with livestock keepers' cattle trait preferences. Second, to estimate the importance of different transaction costs that farmers encounter while accessing breeding services that confer the preferred traits. The information generated would be used to select specific production systems in which to disseminated the Orma Boran and also identify the dissemination approach to use in the dissemination program. This study established that jointly, farmers in Kwale County preferred cattle that are resistant to trypanosomiasis, were of large body size, resistant to TBDs, and are have high milk output, in that order. However, there were inter-production system differences where TBD resistance was least valued in agro-pastoral system, with most emphasis being put on size of animal and trypanosomiasis resistance in that order. On the other hand, TBD resistance were valued above trypanotolerance and body size in pastoral and mixed production systems. Regarding transaction costs, price was identified as the most important attribute in the choice of breeding services. Price of service was rated so highly to the extent that increasing price from the subsidised levels to existing market prices for AI breeding services charges was sufficient enough to discourage many farmers from choosing stimuli with higher price. While farmers in pastoral and mixed systems preferred natural bull service to AI, those in agro-pastoral system preferred the reverse. Distance was the least important of the three transaction cost attributes. Since the improved trypanotolerant Orma Boran has not been breed to confer TBD resistance above the breeds currently kept by communities residing in Kwale, it was concluded that the most likely initial introductory area for the breed would be in the agro-pastoral zone. Furthermore, whereas natural service was preferred over AI service in pastoral and mixed system, AI was given preference in agro-pastoral system. This implies that the Orma dissemination strategy in these target areas should encompass low priced-AI services, for the start, with the use of breeding bulls where infrastructures supportive of AI may be lacking.

\section{Acknowledgement}

This study was funded by the National Research Fund, NRF. The authors acknowledge the farmers of Kwale County, Kenya and the 
facilitation provided by the Director, Kenya Agricultural and Livestock Research Organisation towards making the study successful. The willingness of Kwale County

\section{References}

Budd, L. 1999. DFID-funded tsetse and trypanosome research and development since 1980. Vol. 2. Economic analysis. Aylesford, UK, DFID Livestock Production, Animal Health and Natural Resources Systems Research Programmes.

d'Ieteren G. D., E Authié, N. Wissocq, \& Murray M. 1998. Trypanotolerance, an option for sustainable livestock production in areas at risk from trypanosomiasis. Rev Sci Tech. 17(1): 154-75.

Dolan R. B. 1998. The Orma Boran: A trypanotolerant East African breed. Fifteen years of research on Galana Ranch in Kenya. Kenya Trypanosomiasis Research Institute, Kikuyu, Kenya

Caron A, Miguel E., Gomo, C., Makaya, P., Pfukenyi, D.M, Foggin, C., Hove, T., \& De Garine-Wichatitsky, M. 2013. Relationship between burden of infection in ungulate populations and wildlife/livestock interfaces. Epidemiology and Infection. 141: 15221535.

Eisler, M., Torr, S., Machila, N., Coleman, P. \& Morton, J. 2002. Integrated control of ticks and tsetse: epidemiological, social and economic implications. Integrated Control of Pathogenic Trypanosomes and their Vectors (ICPTV) Newsletter No. 6. pp 7-8.

Food and Agriculture Organization (FAO) of the United Nations. 1996. Agro-Ecological Zoning Guidelines. FAO Soils Bulletin 73. Soil Resources, Management and Conservation Service. FAO Land and Water Development Division. Rome. Available at: http://www.fao.org/3/w2962e/w2962 e00.htm\#P-2.

Green, P. E., \& Srinivasan, V. 1978. Conjoint Analysis in Consumer Research: Issues and Outlook. Journal of Consumer leadership in supporting uptake of Orma Boran is acknowledged.

Research. 5: 103-123. http://www.jstor.org/stable/2489001

Holbrook Morris B. 1981. Introduction: The Esthetic Imperative in Consumer Research, in SV - Symbolic Consumer Behavior, eds. Elizabeth C. Hirschman and Morris B. Holbrook, New York, NY: Association for Consumer Research. Pages: 36-37.

Jaetzold, R., \& Schmidt, H. 1983. Farm Management Handbook of Kenya. East Kenya 2(1): 245-285). Kenya: Ministry of Agriculture.

Jain, A. K., Acito, F, Malhotra, N,K, \& Mahajan, V. 1979. A Comparison of the Internal Validity of Alternative Parameter Estimation Methods in Decompositional Multi-attribute Preference Models. Journal of Marketing Research 16: 313-22.

Kristjanson, P.M., Swallow, B.M. Rowlands, G.J. Kruska R.L. \& de Leeuw P.N. 1999. Measuring the costs of African animal trypanosomiasis, the potential benefits of control and returns to research. Agricultural Systems 59: 79-98.

Kwale, County Government. 2018. Kwale County Integrated Development Plan (20182022). https://kecosce.org/kwalecounty-integrated-development-plan2018-2022/

Ladd, G.W. \& Gibson C., 1978. Microeconomics of Technical Change: What's a better Animal Worth? American Journal of Agricultural Economics, 60: 236-240.

Ladd, G. W. \& Suvannunt, V., 1976. A Model of Consumer Goods Characteristics American Journal of Agricultural Economics, 58 (3), 504-510. http:/ /links.jstor.org/sici?sici=00029092\%28197608\%2958\%3A3\%3C504\%3A AMOCGC\%3E2.0.CO\%3B2-0

Makokha, S.N, Karugia, J.T; Staal, S.J; \& OluochKosura, W. 2007. Valuation of cow attributes by conjoint analysis: A case study of Western Kenya. African Journal of Agricultural and Resource Economics 1 (2): 95-113. 
Maloo S.H., Thorpe W., Kioo G., Ngumi P., Rowlands G.J., \& Perry B.D. 2001a. Seroprevalences of vector-transmitted infections of smallholder dairy cattle in coastal Kenya. Preventive Veterinary Medicine, 52:1-16.

Maloo S.H., Rowlands G.J., Thorpe W., Gettinby G., \& Perry B.D. 2001b. A longitudinal study of disease incidence and casefatality on smallholder dairy farms in coastal Kenya. Preventive Veterinary Medicine, 52:17-29.

Manski, C.F. 1977. The structure of random utility models. Theory and Decision 8: 229254.

Mugunieri, G.L. \& Matete, G.O. 2005. Association of trypanosomiasis risk with dairy cattle productivity in western Kenya. Ondesterpoort Journal of Veterinary Research 72: 279-284.

Munang'andu, H., Siamudaala, V., Musso, M., \& King, N. 2012. Detection of Parasites and Parasitic Infections of Free-Ranging Wildlife on a Game Ranch in Zambia: A Challenge for Disease Control. Journal of Parasitology Research 2012(1):296475. DOI:10.1155/2012/296475

Muraguri G.R., McLeod A., McDermott J.J., \& Taylor N. 2005. The incidence of calf morbidity and mortality due to vectorborne infections in smallholder dairy farms in Kwale District, Kenya. Veterinary Parasitology,130 (3-4):305-15. doi: 10.1016/j.vetpar.2004.11.026. PMID: 15885914.

Njogu, A.R., Dolan. R.B. Wilson, A.J and Sayer, P.D. 1998. Trypanotolerance in the East African Orma Boran cattle. Veterinary Record, 17 (24): 632-636.

Okal, M.N., Odhiambo B.K., Otieno P, Bargul, J.L., Masiga D., Villinger J., and Kalayou, S. Microorganisms 2020, 8, 1830. doi:10.3390/microorganisms 8111830

Ouma, E, Awudu, A. \& Adam D. 2007. Measuring Heterogeneous Preferences for Cattle Traits among Cattle-Keeping Households in East Africa. American Journal of Agricultural Economics 89 (4): 1005-1019.

Randolph, T. \& Ndung'u, L. 2000. 'Gender and transaction cost: A conjoint analysis of choice of livestock health service among smallholder dairy farmers in Kenya'. Background paper for poster presented at the XXIVth Congress of the IAAE Berlin, 18-24 August 2000.

Scarpa, R., Ruto Eric, S.K., Kristjanson, P., Radeny, M., Drucker, A. G., \& Rege, J. E.O., 2003. Valuing indigenous cattle breeds in Kenya: an empirical comparison of stated and revealed preference value estimates, Ecological Economics 45: 409-426.

SPSS. 1994. SPSS for Windows, Categories 6.1. SPSS Inc. Chicago.

Sy, H. A., Faminow, M.D., Johnson G.V., \& Crow G., 1997. Estimating the values of cattle characteristics using an Ordered Probit model. American Journal of Agricultural Economics 79 (2): 463-476.

Tano K., M. Kamuanga, Merle D. Faminow \& Swallow B. 2003. Using conjoint analysis to estimate farmer's preferences for cattle traits in West Africa. 2003. Ecological Economics 45 (3): 393-407.

Wittink D. R., Krishnamurthi L. \& Reibstein, D.J. 1989. The effect of differences in the number of attribute levels on conjoint results. Marketing Letters, 1:2: 113-123.

Wollny C.B. 2002. The Need to Conserve Farm Animal Genetic Resources in Africa: Should Policy Makers be concerned? Ecological Economics 45 (3): 341-351 